\title{
DE LA TRANSFORMACIÓN A LA BANCARIZACIÓN DE LAS CAJAS DE AHORROS ESPAÑOLAS: UN ANÁLISIS DE LOS RESULTADOS PERSEGUIDOS
}

\author{
POR \\ Milagros GUTIÉRREZ FERNÁNDEZ ${ }^{1}$ \\ Yakira FERNÁNDEZ TORRES ${ }^{2}$ \\ Ricardo PALOMO ZURDO ${ }^{3}$
}

\section{RESUMEN}

Esta investigación tiene su origen en el proceso de reordenación que ha acontecido en el sector bancario español. Dicha reestructuración se ha llevado a cabo para tratar de reducir las dudas sobre la viabilidad de las entidades bancarias a medio y largo plazo y así poder restituir de nuevo la confianza en el sector. Aunque la crisis económico-financiera ha afectado a todo el sector bancario, ha sido el subsector de las cajas de ahorros el que ha experimentado la mayor transformación mediante fusiones, absorciones y a través de Sistemas Institucionales de Protección -SIP-, y el que se ha visto sometido al denominado proceso de bancarización. Considerando lo anterior, la presente investigación se centra en el estudio de las cajas de ahorros para trata de comprobar si dicha transformación y consiguiente proceso de bancarización ha permitido que se satisfagan los objetivos perseguidos con la reordenación bancaria. Para ello, se analiza la evolución de magnitudes económico-financieras relevantes para el sector bancario durante el período comprendido entre 1999 y 2012. Los resultados sugieren que no todas las cajas de ahorros han visto mejorados sus ratios de eficiencia, solvencia, brecha financiera y obra social, lo que indica que aún queda bastante por hacer para lograr solventar los problemas que afectan al sector estudiado.

Palabras clave: Cajas de ahorros, reestructuración bancaria, eficiencia, solvencia, obra social, brecha financiera, bancarización.

\footnotetext{
${ }^{1}$ Universidad de Extremadura, mgutierrezf@unex.es.

${ }^{2}$ Universidad de Extremadura, yakiraft@unex.es.

${ }^{3}$ Universidad CEU San Pablo, palzur@ceu.es.

REVESCO No 122 - Tercer Cuatrimestre 2016 - ISSN: 1885-8031 - www.ucm.es/info/revesco

http://dx.doi.org/10.5209/rev_REVE.2016.v122.52022
}

Fecha de recepción: 18/11/2015

Fecha de aceptación: 29/02/2016 
Claves ECONLIT: G01, G21, G34, P30.

\title{
FROM THE TRANSFORMATION TO THE BANCARIZATION OF SPANISH SAVING BANKS: AN ANALYSIS OF THE RESULTS PURSUED
}

\begin{abstract}
This research arises due to the current restructuring process in which is immersed the Spanish banking sector. The above mentioned process is carried out to try to reduce the doubts on the viability of the bank companies to average and long term and to be able to return again the confidence in the sector. Though the economic and financial crisis has concerned the whole banking sector, the subsector of the Spanish savings banks is the one that has experienced a major number of integrations (articulated by means of mergers, absorptions and across Institutional Protection Schemes -IPSs-), and the one that has met submitted to the bancarization process. Considering what has been said, the present paper analyses Spanish saving banks to try to discern whether thanks to that process the objectives pursued by the bank rearrangement have been fulfilled. To do this, the evolution of some important financial variables will be studied over a long period of time (1999-2012). The results suggest that not all the savings banks have seen improved their ratios of efficiency, solvency, financial gap and social work, which indicates that there is still much to be done in order to rectify the problems affecting the studied sector.
\end{abstract}

Keywords: Saving banks, bank restructuring, efficiency, solvency, social work, financial gap, bancarization.

\section{INTRODUCCIÓN}

La presente investigación surge a tenor de lo acaecido en el sector bancario en España, así como en gran parte del mundo, tras la crisis económico-financiera de verano de 2007. Según Gutiérrez, Palomo y Fernández (2013), dicha situación llevó a una importante reestructuración en las entidades financieras con el objetivo de solucionar los problemas de liquidez, morosidad y solvencia en los que se encontraban inmersos. Las principales entidades financieras afectadas fueron las cajas de ahorros, que debieron acometer procesos de fusión y absorción, tratando así de reducir su exceso de capacidad instalada, y por tanto los costes asociados a su mantenimiento, lo que les conduciría a una mejora en su eficiencia (Banco de España, 2012); pero también al objeto fundamental de reducir los graves problemas de 
solvencia en que se encontraron muchas de ellas al aumentar desproporcionadamente su cartera de activos fallidos y morosos.

Además de las tradicionales fusiones, una de las soluciones empleadas por las instituciones financieras para combatir la crisis fue la utilización de los denominados sistemas institucionales de protección (SIP), surgidos a raíz del Real Decreto-Ley 6/2010, de 9 de Abril, que modificó la Ley 13/1985 e implantó la anterior figura jurídica. Este sistema, también denominado fusión fría o fusión virtual, otorgó la posibilidad de poder superar los obstáculos político-regionales a las fusiones entre entidades de diferentes comunidades y se ha basado en la creación de una modalidad heterodoxa de holding, es decir, una sociedad financiera que controla la mayoría de las acciones de un grupo de empresas, formado por distintas entidades que tienen cierta independencia, y la creación de un banco central al que se traspasa todo el negocio financiero de las entidades participantes (Gutiérrez, 2011).

De este modo, con la creación de los SIPs en las cajas de ahorros a partir del año 2010 se pretendió mantener la independencia jurídica de cada entidad que integraba el SIP, así como su identidad comercial y territorial (que en aquel momento se consideraba especialmente importante pero que el paso del tiempo ha confirmado que los clientes demandan es solvencia), de tal modo que cada entidad conserva sus consejos de administración, sucursales, recursos humanos y obra social, elementos todos ellos que parecían facilitar este proceso laxo de concentración y reducir reticencias de carácter político o personal.

Teniendo en cuenta lo anterior, en este trabajo se estudiará el sector de las cajas de ahorros en el período comprendido entre 1999 y 2012, con el objetivo de intentar dar respuesta a la siguiente hipótesis: Analizar si el proceso de reestructuración bancaria de las cajas de ahorros ha contribuido a mejorar sus resultados respecto a variables relevantes como la eficiencia, la solvencia, la brecha financiera o la obra social.

Cabe destacar que el proceso de reestructuración se ha llevado a cabo para reducir las dudas sobre la viabilidad de las entidades bancarias a medio y largo plazo y así poder restituir de nuevo la confianza en el sector; por tanto, lo que se intenta con este proceso es disminuir los problemas de liquidez y solvencia ante situaciones futuras y así poder reparar los balances de las entidades con problemas (Miralles y Daza, 2011). Por tanto, se trata de comprobar si como consecuencia del proceso de bancarización de las cajas de ahorros se han visto 
cumplidos los objetivos perseguidos con la reordenación bancaria.

El trabajo se organiza en tres secciones además de esta primera de introducción. En la segunda parte se va a tratar de explicar brevemente el proceso de reestructuración y su impacto en las cajas de ahorros. En el tercer epígrafe quedan reflejados los datos utilizados para el estudio, así como las variables empleadas y el análisis realizado. Por último, en el cuarto apartado se muestran las conclusiones del estudio.

\section{LA REESTRUCTURACIÓN BANCARIA Y SU IMPACTO EN LAS CAJAS DE AHORROS}

El intenso proceso de reorganización y reestructuración que ha caracterizado durante los últimos años al sector bancario español es, hasta la fecha, el más intenso de su historia pues, tanto por su dimensión como por su especial trascendencia en el caso de las cajas de ahorros (a excepción de las dos entidades de menor dimensión del sector ${ }^{4}$ ) todas las demás se han transformado en bancos, acompañados de sus respectivas fundaciones bancarias.

Este intenso proceso se enmarca dentro de la reestructuración bancaria global producida tanto en España como en la mayor parte de los países europeos, así como en Norteamérica, durante los últimos años; y tanto en la banca de inversión como en la banca minorista, más abundante en Europa (Rughoo y Sarantis, 2014 y Efthyvoulou y Yildirim, 2014).

Mientras en el subsector de la banca se han producido algunas fusiones e integraciones ( $\sin$ necesidad de rescate o intervención), en las anteriores cajas de ahorros (que representaban una cuota de mercado del $50 \%$ del sector bancario español) se pasó, entre los años 2009 a 2012, de 45 a sólo 13 entidades (Confederación Española de las Cajas de Ahorros-CECA-, 2015), principalmente mediante absorciones o mediante la formación de sistemas institucionales de protección (SIP). En el caso de las cooperativas de crédito, también la figura de los SIP ha protagonizado algunos de los principales procesos de consolidación.

Por otra parte, el sector bancario debe hacer frente a la confluencia de cambios normativos muy relevantes, como son los requerimientos de Basilea III, los que afectan a su modelo de negocio y otros muy diversos como los mecanismos de resolución de las entidades con problemas, las pruebas de estrés, etc. Asimismo, la actual crisis económica ha conllevado

\footnotetext{
${ }^{4}$ Son los casos de las cajas de ahorros de Ontinyent y de Pollensa.
} 
la necesidad de crear un mercado único bancario, para lograr una revisión única a nivel europeo, para que los ahorradores tengan una seguridad sobre sus ahorros a través de un fondo de garantía de depósitos europeo y un mecanismo europeo de resolución de crisis bancarias, pero en este último fin varía de unas zonas a otras.

De este modo, algunos países decidieron suministrar grandes cantidades de capital público a los bancos con problemas, sin someterlos a la vez a una reestructuración de dichas entidades. Pero, otros países, como por ejemplo España, primeramente hicieron frente a la crisis con una reestructuración bancaria suministrando una proporción limitada de capital público, restringido a efectuar los planes de viabilidad.

Por esta razón, en junio de 2012, la Comisión Europea realizó una propuesta de directiva que fijaba un marco para el rescate y resolución de entidades de crédito y que fue tenida en cuenta a la hora de promulgar el RDL 24/2012 de reestructuración y resolución de entidades de crédito en España.

Todos estos cambios normativos especialmente centrados en la solvencia de las entidades han afectado también a su capacidad crediticia, con un negativo efecto sobre la economía real y una contracción en la dimensión del sector con claros efectos negativos sobre el empleo que ha sido especialmente intenso hasta el año 2014.

Bajo este planteamiento se adivina una adaptación del tamaño de la empresa para la búsqueda de la eficiencia (Homma, Tsutsui y Uchida, 2014), pues el aumento del tamaño de la entidad conlleva a obtener determinadas ventajas estratégicas y económicas, algunas son, por ejemplo: la reducción del número de oficinas, economías de escala, alto respaldo para la entidad ante problemas de solvencia y/o liquidez (Rhoades, 1998; Berger, De Young y Udell, 2001; Fuentes, 2003).

Todo lo anterior lleva a la pérdida de las entidades menos competitivas, por lo que quedan solo las más eficientes y rentables y provoca un aumento de la eficiencia empresarial y la rentabilidad (Palomo y Sanchis, 2010). Por tanto, lo que se pretende con este proceso de reordenación es el aumento del tamaño de las entidades que están en el mercado para enriquecer la solvencia y la competitividad a través de su reducción de costes, fidelización de clientes y de la capacidad de integración de las entidades. 


\subsection{Resultados del proceso de reorganización bancaria}

Como se ha expuesto previamente, la reordenación que ha transformado el mapa bancario español y, sobre todo, el de las cajas de ahorros, se ha instrumentado mediante fusiones y adquisiciones; aunque también, una de fórmulas ampliamente utilizada ha sido la de los sistemas institucionales de protección (SIP), en la que los integrantes mantienen su identidad propia y su capacidad operativa en el plano comercial, así como su independencia económica, pero poniendo en común un diverso grado su solvencia y resultados de la actividad (Palomo, Sanchis y Gutiérrez, 2011).

En el subsector de los bancos, la crisis financiera ha motivado algunas operaciones de concentración en las que se han involucrado tanto bancos como cajas de ahorros; siendo algunos de dichos bancos, nuevas entidades procedentes de las anteriores cajas de ahorros. No obstante, es en las cajas de ahorros donde se han producido los mayores desequilibrios, derivados de la expansión crediticia, que registraron en el período previo a la crisis (Gutiérrez, Palomo y Romero, 2012). Destaca el exceso de capacidad instalada en el sector y la elevada exposición al sector inmobiliario y constructor, con la consecuente elevación de la tasa de morosidad y la dificultad de acceso a la financiación de los mercados mayoristas ${ }^{5}$.

Como consecuencia de lo anterior, las cajas de ahorros han llevado a cabo la mayor consolidación bancaria realizada en España que, hasta el año 2013, fecha de asentamiento del proceso de consolidación del sector, se había concretado en tres fusiones puras y tres por absorción, tres integraciones mediante la modalidad de SIP (uno de los cuales -Bankia- fue nacionalizado), dos entidades sin proceso y una caja intervenida en agosto de 2011, la Caja de Ahorros del Mediterráneo (CAM), integrada finalmente con el Banco Sabadell. A lo anterior deben añadirse los procesos acaecidos con anterioridad (entre los que se encuentran la constitución de Banca Cívica, Liberbank y Caja 3 mediante SIP o las fusiones de la Caixa y Caixa Girona, o la de Unicaja con Caja Jaén, entre otras), y las dos cajas rescatadas por el Banco de España en 2009 y 2010, respectivamente: Caja Castilla-La Mancha (CCM) y CajaSur, posteriormente absorbidas por otras entidades.

\footnotetext{
${ }^{5}$ Precisamente, las fusiones y agrupamientos de cajas de ahorros desarrolladas desde el año 2010 han 1 levado a la constitución de varios bancos que han recogido el negocio bancario de las cajas que los han originado. Su constitución como sociedades anónimas e incluso su salida a bolsa a partir de junio de 2011 ha sido el modo de transformar su capacidad para ser solventes.
} 
Figura 1: El proceso de reordenación de las cajas de ahorros y sus resultados

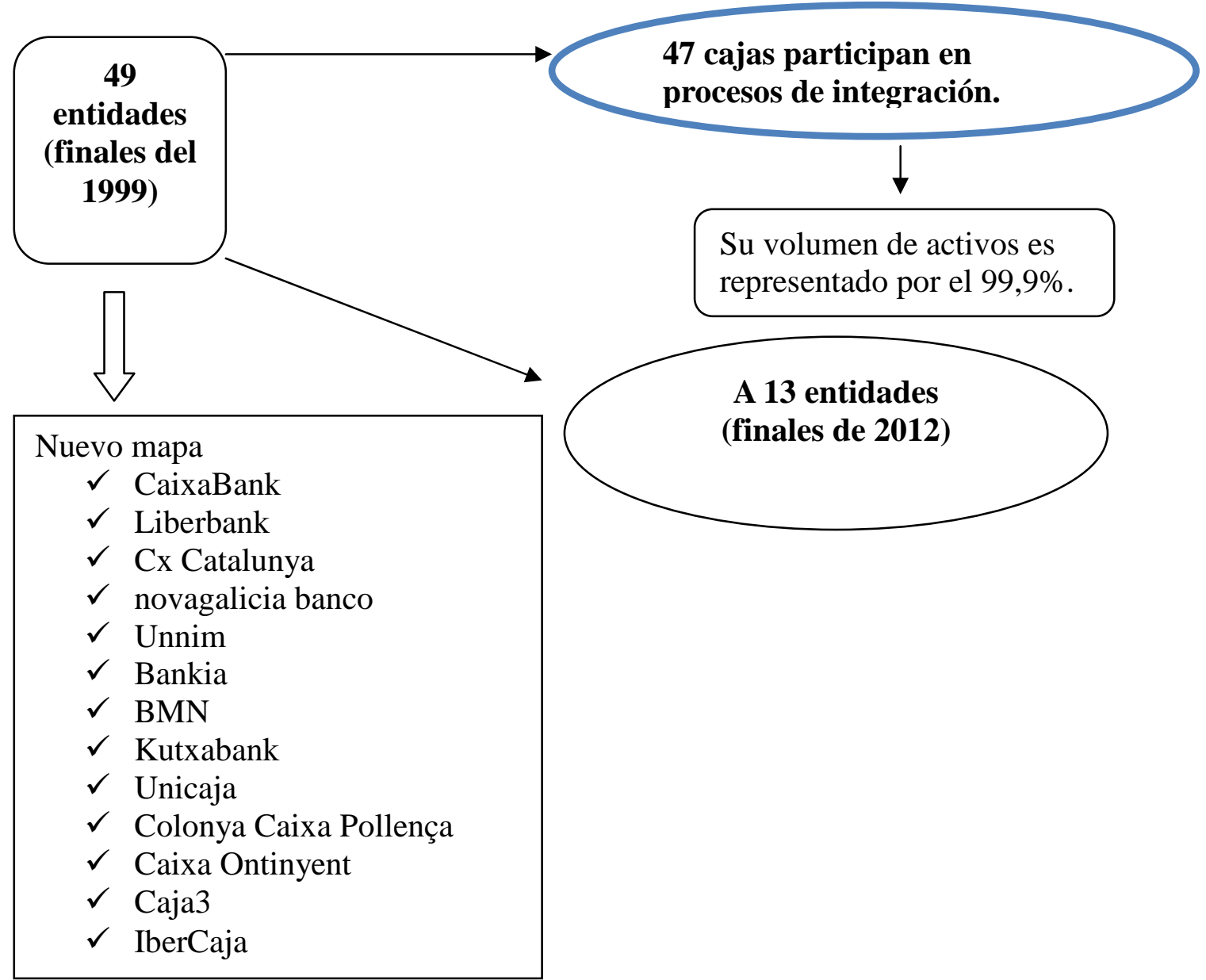

Fuente: Elaboración propia en base a Ceca (2015).

Según la Confederación Española de Cajas de Ahorros -CECA-, el proceso acaecido ha sido el mayor de la historia de las cajas de ahorros, y se ha basado en las claves que se exponen a continuación, siendo sus tres objetivos fundamentales la consolidación, la eficiencia y la transparencia:

Existencia de stakeholders (personas o entidades afectadas por las actividades que lleva a cabo una empresa) en los órganos del gobierno.

$>$ Vínculo local/territorial.

Banca relacional, basada en la relación ajustada entre los bancos y los prestatarios que puede ser beneficiosa económicamente.

$>$ Colaboración entre entidades para mantener la recíproca competencia.

$>$ Mantenimiento de la Obra Social. 


\subsection{Efectos de la reorganización bancaria}

Una vez referido el proceso de reorganización de las cajas de ahorros y sus resultados, se van a resumir a continuación algunos de sus principales efectos:

$\checkmark$ Se limitó el acceso a la financiación en forma de préstamos reclamando a las entidades viabilidad y mejora en la eficiencia, así se exigía un compromiso para disminuir la plantilla y oficinas para reducir el exceso de capacidad.

$\checkmark$ Se generó una gran disminución del número de cajas de ahorros, pasando de 49, a principios de 1999, a tan solo 13 grupos a finales de 2012.

$\checkmark$ El tamaño medio de las cajas de ahorros se triplicó, lo que permitió la generación de economías de escala.

$\checkmark$ Creación de SIPs (Sistemas Institucionales de Protección) permitiendo así la consecución de fusiones interregionales.

Un elemento importante, aunque también controvertido ha sido el coste del proceso de reestructuración de una parte del sector. Según fuentes del Banco de España, las ayudas financieras para la recapitalización del sector han ascendido a 61.336 millones de euros; si bien, el total de fondos públicos aplicados a la reestructuración asciende a 107.913 millones de euros ${ }^{6}$, al sumar los fondos del FROB, del Fondo de Garantía de Depósitos y del Banco de España. Cabe indicar que la banca "sana" ha destinado 7.557,2 millones de euros, fundamentalmente en aportaciones al Fondo de Garantía de Depósitos (FGD) y a la Sociedad gestora de activos procedentes de la reestructuración bancaria (SAREB). Más concretamente, por entidades, Banco Santander ha aportado 4.000 millones de euros; Popular, 1.775 millones; Caixabank, 966,2 millones; Sabadell, 750 millones y Bankinter, otros 66 millones de euros (Banco de España y elaboración propia). Algunos bancos han adquirido entidades durante la crisis: Popular (Banco Pastor), BBVA (Unnim), Sabadell (CAM) y Caixabank (Caixa Girona, Bankpime, Banco de Valencia y Banca Cívica).

Tras haber resumido brevemente la magnitud de la reestructuración bancaria acaecida en el sector de las cajas de ahorros, procede explicar cuáles han sido las fuentes de datos y las variables utilizadas para contrastar la hipótesis de partida que tratará de analizar si debido a la bancarización surgida como consecuencia de la reorganización de las entidades objeto de

\footnotetext{
${ }^{6}$ Fuente: Tribunal de Cuentas del Reino de España, 2014.
} 
estudio, éstas han visto incrementados sus resultados respecto a una serie de variables que se consideran clave en dicho proceso.

\section{DATOS, VARIABLES Y RESULTADOS DEL ANÁLISIS}

\subsection{Los datos utilizados y su homogeneización}

La base de datos utilizada está formada por la totalidad del sector de cajas de ahorros españolas durante el período 1999-2012. Esto supone comenzar la serie trabajando con las 49 cajas existentes a 31 de diciembre de 1999 (excluida la propia CECA) para terminarla con 13 cajas o grupos de entidades surgidas como consecuencia de las fusiones (frías o tradicionales) experimentadas por el sector. Por tanto, considerando que la mayor parte de las cajas son el resultado de los procesos de integración expuestos anteriormente y acontecidos en el período temporal analizado, para poder operar y realizar una evolución de tan dispar número de entidades, se ha optado por tener en cuenta, de forma regresiva, el agregado resultante de las cajas fusionadas a efectos del ejercicio correspondiente, aunque lo anterior suponga la creación ocasional de entidades ficticias.

Se han deflactado los datos para trabajar con series adecuadamente homogéneas utilizando para ello dos deflactores: el de los costes laborales de las actividades financieras, empleado para homogeneizar los gastos de personal; y el del valor agregado de la intermediación financiera, utilizado para deflactar el resto de variables consideradas. Ambos deflactores han sido calculados a través de los datos obtenidos del Instituto Nacional de Estadística.

\subsection{Variables empleadas}

El hecho de seleccionar las variables adecuadas para el análisis conlleva una apreciable subjetividad dada la multitud de indicadores que pueden ser seleccionados como consecuencia de la naturaleza de las entidades objeto de estudio. Así, se puede operar con datos directos, como dimensión económica, laboral, etc. En sus múltiples perspectivas; o bien, con ratios económicos u otros índices e indicadores de índole financiera, productiva, etc. Por ello, es preciso efectuar un análisis de campo pormenorizado y detallado para realizar una adecuada selección de las variables que podremos utilizar, teniendo en cuenta la disponibilidad de datos fidedignos y cuantificables. 
En este sentido, teniendo conocimiento de que las entidades objeto de estudio combinan, por su naturaleza jurídica, la faceta económica o bancaria propiamente dicha con la faceta social, se han seleccionado los indicadores ${ }^{7}$ que se han considerado adecuados para reflejar, tanto la dimensión económica como la dimensión social. A continuación se efectúa una descripción de las variables elegidas para realizar el trabajo:

$\checkmark$ Eficiencia técnica: medida como el cociente entre (Gastos de administración+ Amortización) y (Margen Bruto- Otros productos explotación- Otras cargas de explotación). Esta ratio muestra la relación entre los gastos de explotación y el margen de intermediación saneado, por lo que hace referencia a la parte del producto absorbido por el gasto. Cuanto más pequeño sea el valor de este ratio mayor será la eficiencia, esto quiere decir que para la obtención de un determinado margen el consumo de los recursos es menor y viceversa.

$\checkmark$ Gasto en obra social: medida como el cociente entre el volumen de recursos invertidos por las cajas en el desarrollo de la obra social y el Beneficio neto generado por la entidad (Obra social/ Resultado del ejercicio). El principal objetivo es maximizarlo ya que es un indicador sin ánimo de lucro y de carácter fundacional.

$\checkmark$ Solvencia: medida como el cociente de los recursos propios de la entidad y los activos totales medios. Viendo el resultado podremos comprobar si cada entidad es capaz de hacer frente a sus deudas.

$\checkmark$ Brecha financiera: medida como el cociente de créditos y depósitos de la clientela. Cuando el valor de la brecha financiera es superior a 1 o al $100 \%$ significa que los créditos de los clientes es superior a los depósitos.

La eficiencia técnica y la solvencia han sido elegidas como variables por ser los objetivos principales de la reordenación bancaria, mientras que el gasto en Obra Social se ha incorporado por tratarse de entidades fundacionales que deben destinar parte de sus reservas a la Obra Social. Por último, la brecha financiera se ha incluido para analizar si se trata de entidades productivas o no, y por ser un indicador muy utilizado en los cambios de ciclo económico.

\footnotetext{
${ }^{7}$ La elección de los indicadores se ha basado en la revisión bibliográfica de trabajos en materia de entidades financieras y, particularmente, de entidades financieras con un componente social como las cajas de ahorros y las cooperativas de crédito, habitualmente caracterizadas como entidades financieras de economía social.
} 


\subsection{Resultados del estudio}

Para analizar la hipótesis de partida, y estudiar si la reestructuración bancaria ha hecho que las cajas de ahorros mejoren sus resultados de eficiencia, solvencia, brecha financiera y obra social, se toma como punto de partida el informe de Oliver Wyman del año 2012, pues se considera un referente aceptable y objetivo para hacer una clasificación de las entidades analizadas en función de algún parámetro, habiendo sido el establecido las ayudas públicas recibidas. De este modo, en el grupo 0 aparecen recogidas aquellas entidades que han sido intervenidas por el FROB al haber tenido problemas de capitalización. El grupo 1 integra entidades con déficit de capital y con necesidad de financiación, es decir, de ayudas públicas.

El grupo 2 son entidades sin déficit o saneadas. Y por último, el grupo 3 es un grupo de creación propia que se ha incluido para estudiar aquellas entidades que no han experimentado ningún proceso de integración.

Tabla 1: Agrupación de las cajas de ahorros según las ayudas públicas recibidas.

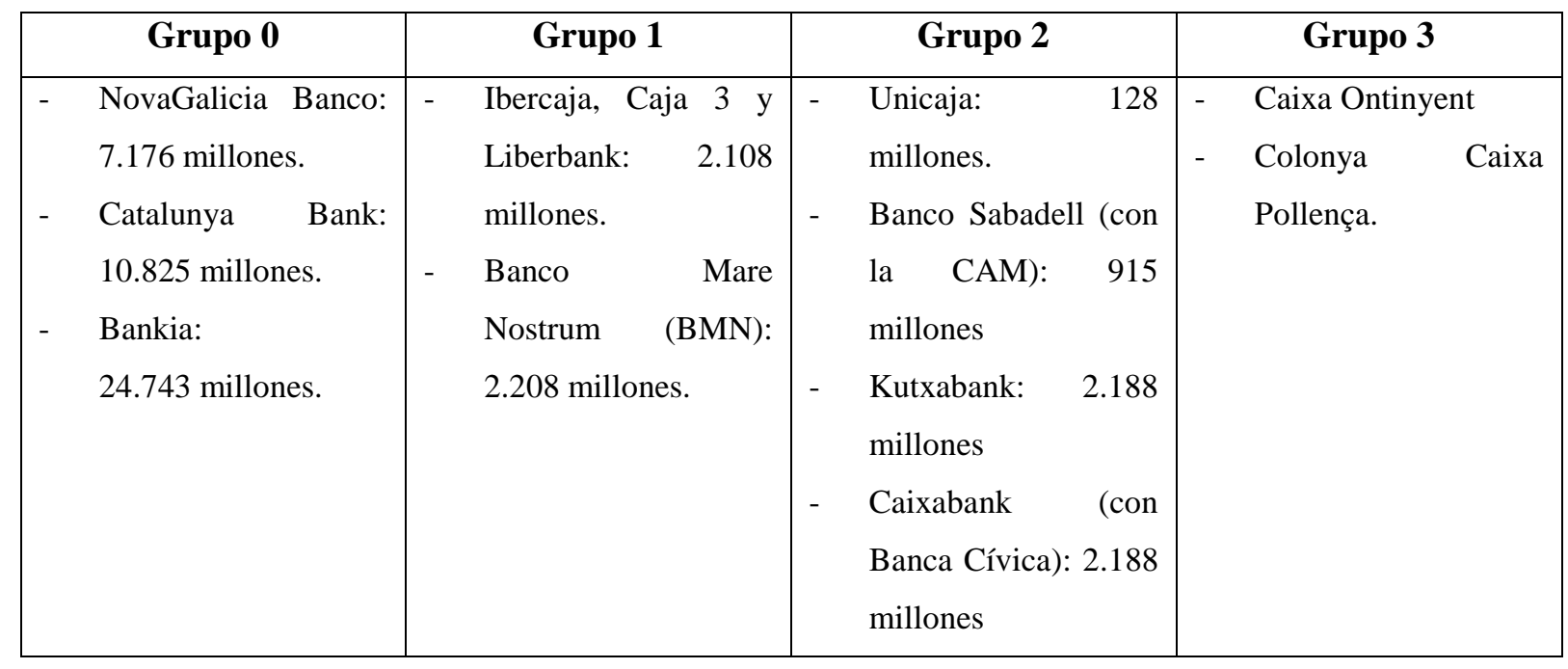

Fuente: Elaboración propia.

Vamos a ver los resultados de cada grupo en función de cada variable seleccionada y su respectiva evolución a lo largo de los años objeto de estudio.

\subsubsection{Análisis de la eficiencia en las cajas de ahorros}

La primera variable que se estudia es la eficiencia de las cajas de ahorros para analizar si gracias a la reestructuración bancaria se ha visto mejorada o si por el contrario, las uniones acaecidas han deteriorado la situación de algunas cajas.

El gráfico 1 muestra cómo las entidades intervenidas por el FROB registran un 
deterioro de su eficiencia a partir del año 2009, pues la ratio se ve incrementada (recordemos que cuanto mayor es la ratio peor es la eficiencia técnica de la entidad). Lo anterior se debe a la crisis económica surgida en 2007, que afecta a las entidades con posterioridad. En dicho momento (2009) comienzan a fraguarse las uniones entre entidades, pero a pesar de lo anterior, y aunque observamos una mejoría en la eficiencia de las entidades entre los años 2010 y 2012, no llega a ser suficiente para resolver los fuertes incrementos experimentados en la ratio en los años previos. Esta puede haber sido una de las causas por las que las entidades analizadas han tenido que ser intervenidas por el FROB.

Gráfico 1: Evolución de la eficiencia en las ajas intervenidas por el FROB (Grupo 0)

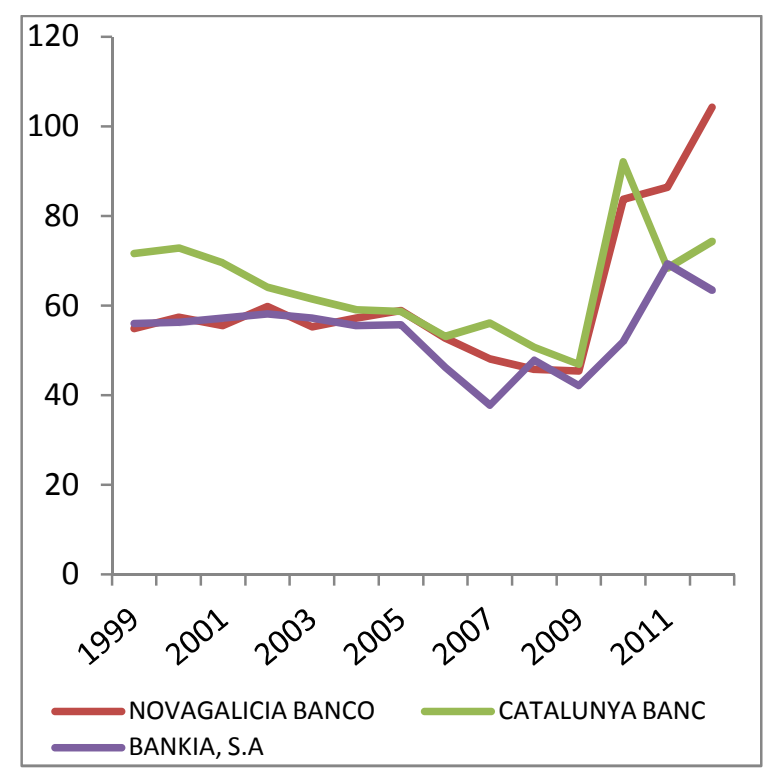

Fuente: Elaboración propia en base a los Anuarios Estadísticos de la CECA (1999-2012).
Gráfico 2: Evolución de la eficiencia en las cajas deficitarias (Grupo 1)

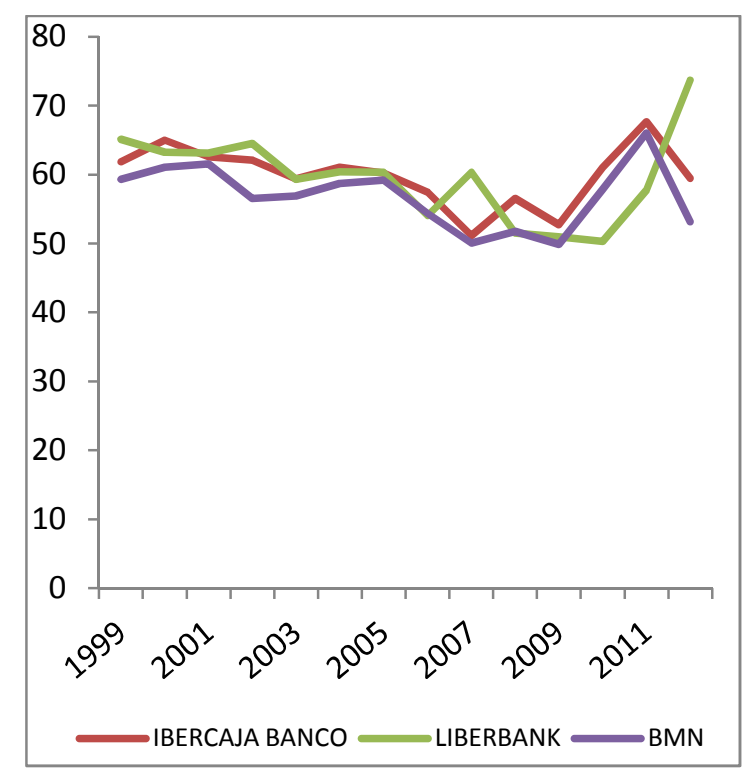

Fuente: Elaboración propia en base a los Anuarios Estadísticos de la CECA (1999-2012).

En el gráfico 2 se observa cómo, en el caso de BMN, hay una mejora de la eficiencia a partir del SIP que se produce en 2010, aunque su situación no ha variado mucho, con un registro de 57,87\% en 2010 y un 66,01\% en 2011; y en Ibercaja también ha mejorado a partir del SIP del Banco Caja 3 y el traspaso del indirecto de Ibercaja a Ibercaja Banco producido a principios del 2011.

Respecto a Liberbank, se produce el caso contrario, es a partir de la unión de Cajastur con Caja Extremadura y Caja Cantabria (a través de un SIP o fusión fría) cuando empeora la eficiencia de esta entidad. La eficiencia técnica de esta entidad empeora en el último año, alcanzando un $73,70 \%$ en 2012. Se puede observar en el gráfico cómo a partir del 2011, 
cuando se produce el dicho SIP, aumenta notablemente su porcentaje de eficiencia técnica. Por tanto, podríamos decir que en este caso la integración a través del SIP ha sido desfavorable para esta entidad en cuanto a la variable de eficiencia técnica se refiere.

Gráfico 3: Evolución de la eficiencia en las cajas sin déficit (Grupo 2)

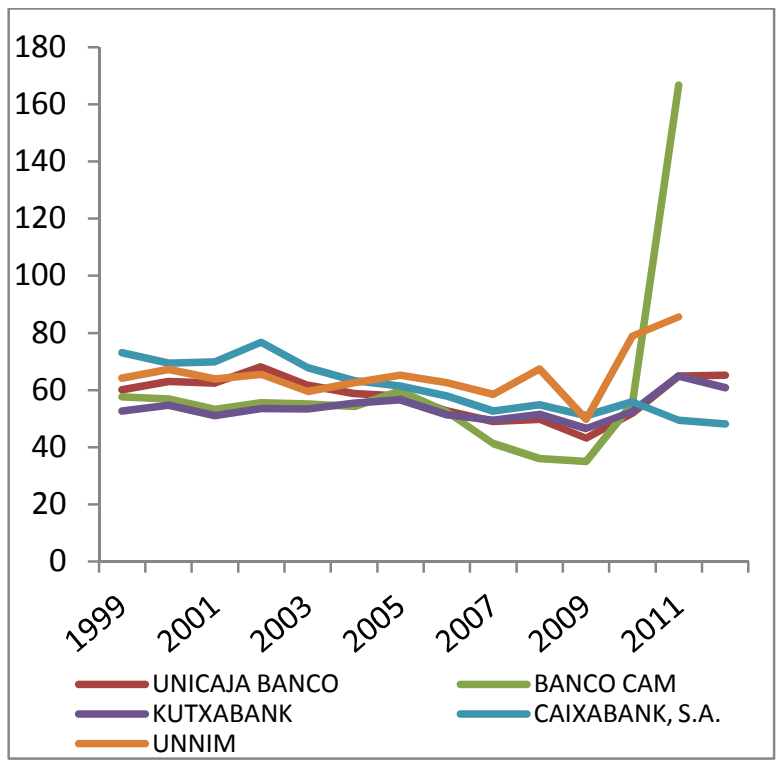

Fuente: Elaboración propia en base a los Anuarios Estadísticos de la CECA (1999-2012).
Gráfico 4: Evolución de la eficiencia en las cajas sin proceso de integración (Grupo 3)

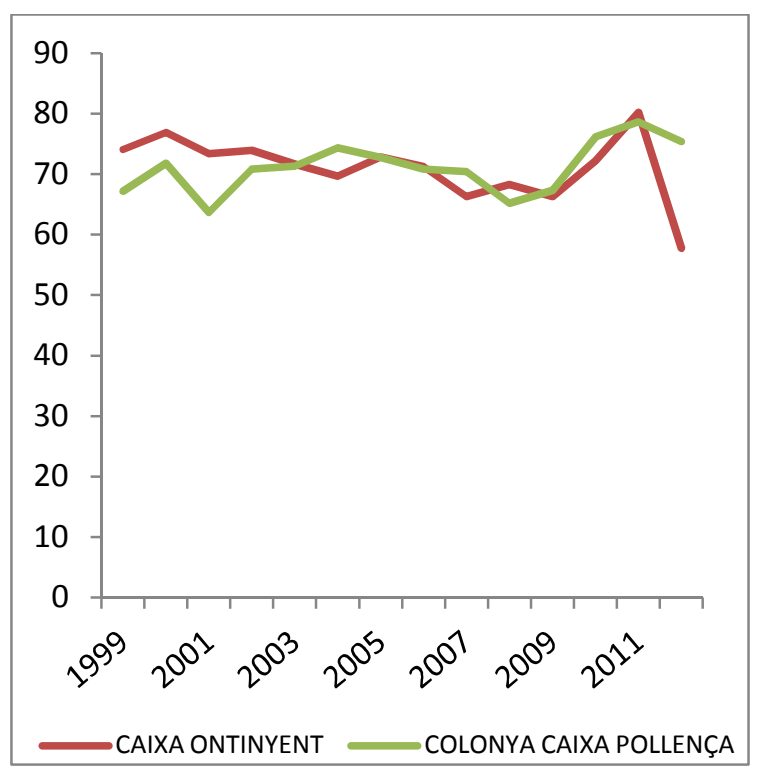

Fuente: Elaboración propia en base a los Anuarios Estadísticos de la CECA (1999-2012).

En el gráfico 3 la entidad con peor nivel de eficiencia es Banco CAM en el año 2011, razón por la cual a partir de este año ha sido integrada por el Banco Sabadell. La entidad más destacable con mejor eficiencia en el Grupo 2 es Caixabank, habiendo mejorado su evolución sustancialmente a pesar de las circunstancias adversas. Así, a partir del 2010 empieza a mejorar la eficiencia de esta entidad, pasando de un 55,81\% en 2010 a un 48,18\% en 2012, lo cual puede haber sido debido en parte al SIP entre Cajasol y Banca Cívica y la fusión de Caixabank con Banca Civíca. En el resto de entidades integradas en este grupo la eficiencia no ha sido muy variable, lo cual es una señal positiva. A excepción de Unnim, que sí la ha visto empeorada, por lo que fue rescatada y vendida a BBVA.

En las entidades del grupo 3 (recogidas en el gráfico 4), a pesar de no tener ningún tipo de proceso, la evolución de su eficiencia ha tendido a mejorar considerablemente, siendo la reducción de la ratio más notable a partir del 2011, aunque hasta llegar a esa mejora ha tenido variaciones a lo largo de los años. Por ejemplo, en el caso de Colonya Caixa Pollença, esta entidad se ha mantenido con pocas variables a lo largo del tiempo, aunque hay que destacar en el período $2011-2012$ ha pasado de $78,62 \%$ a un $75,34 \%$. 


\subsubsection{Análisis del gasto en Obra Social de las cajas de ahorros}

Como se ha expuesto previamente, las cajas de ahorros son entidades con un claro componente social, por lo que es imprescindible tomar esta variable en consideración a la hora de hacer el estudio de nuestras entidades. Asimismo, la CECA entiende que una de las claves del proceso de reestructuración debe ser el mantenimiento de la obra social, convirtiéndose por tanto en esencial su estudio para ver si efectivamente se ha producido una mejora o al menos un mantenimiento de la misma.

Gráfico 5: Evolución del gasto en obra social en las cajas intervenidas por el FROB (Grupo $0)$

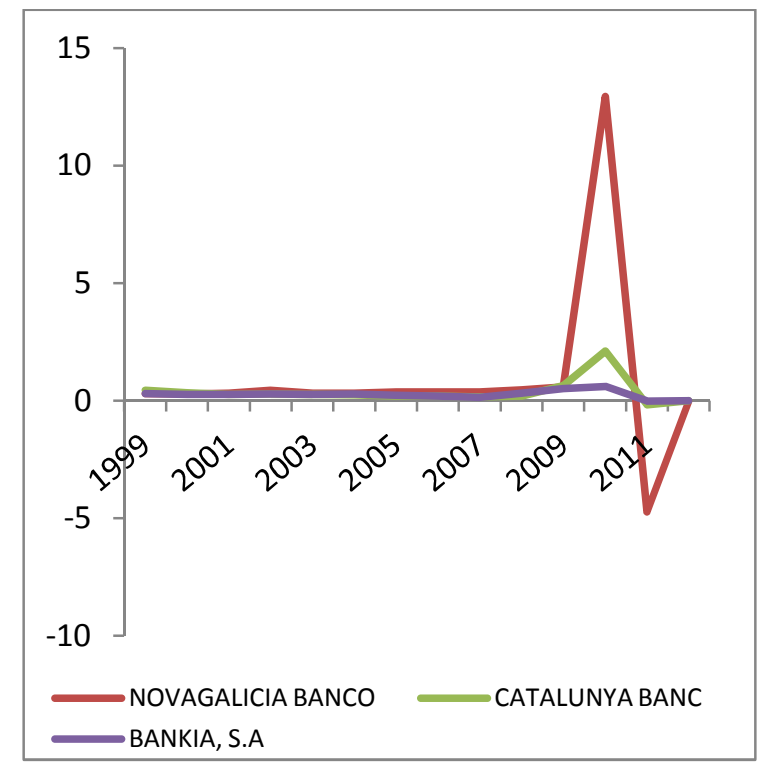

Fuente: Elaboración propia en base a los Anuarios Estadísticos de la CECA (1999-2012).
Gráfico 6: Evolución del gasto en obra social en las cajas deficitarias (Grupo 1)

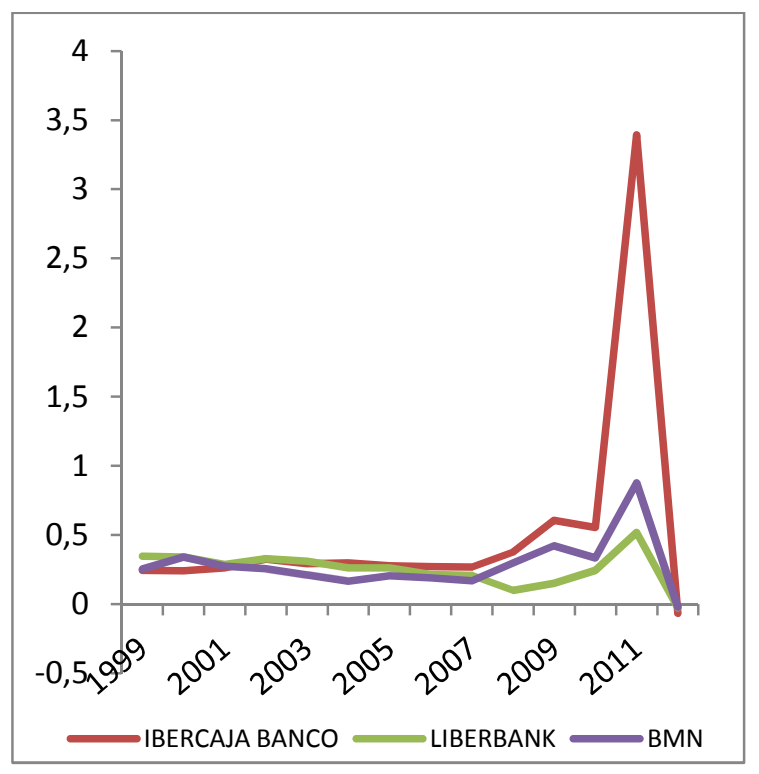

Fuente: Elaboración propia en base a los Anuarios Estadísticos de la CECA (1999-2012).

Si se analiza el gráfico 5, podemos destacar que las entidades que han sido intervenidas por el FROB han mantenido más o menos constante su gasto en Obra Social, aunque destaca Novagalicia Banco, con un dato atípico en el año 2010, que se reduce drásticamente cuando se produce la fusión, para volver a elevarse en el año 2011.

En el gráfico 6 aparecen reflejadas las tres entidades que forman el grupo 1, que han tendido a reducir su gasto en Obra Social entre 2010 y 2012, con incrementos en 2011. Ibercaja es la única que experimenta una gran variación pasando de un gasto en Obra Social de 0,5 en 2010 aproximadamente, elevándose hasta 3,4 puntos en 2011 y luego se produce 
una fuerte bajada llegando a un nivel por debajo de 0 en 2012. Es la entidad con el menor nivel en gasto de Obra Social, a pesar de que en 2009 era una de las entidades con mayor nivel de gasto en Obra Social.

Gráfico 7: Evolución del gasto en obra social en las cajas sin déficit (Grupo 2)

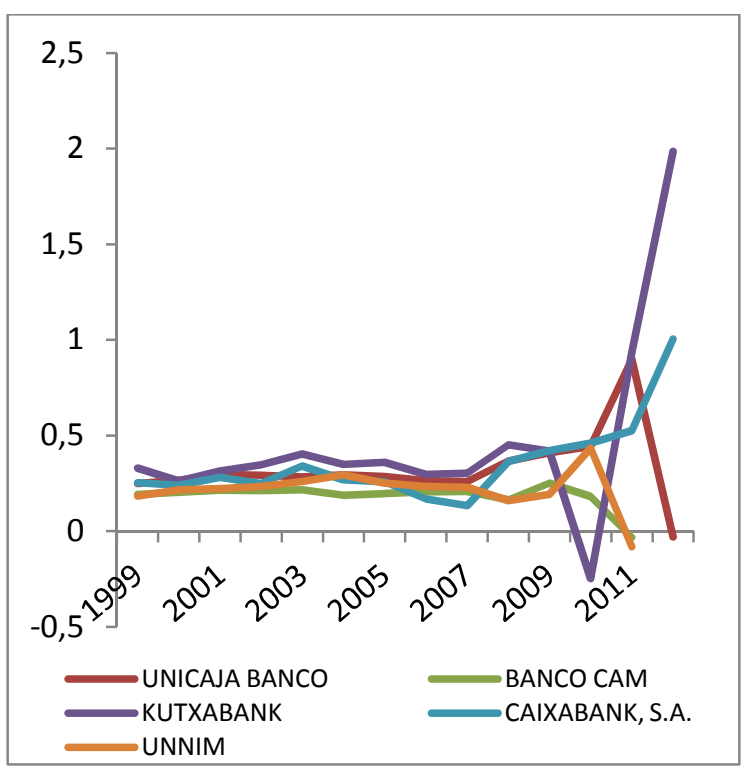

Fuente: Elaboración propia en base a los Anuarios Estadísticos de la CECA (1999-2012).
Gráfico 8: Evolución del gasto en obra social en las cajas sin proceso de integración (Grupo

3)

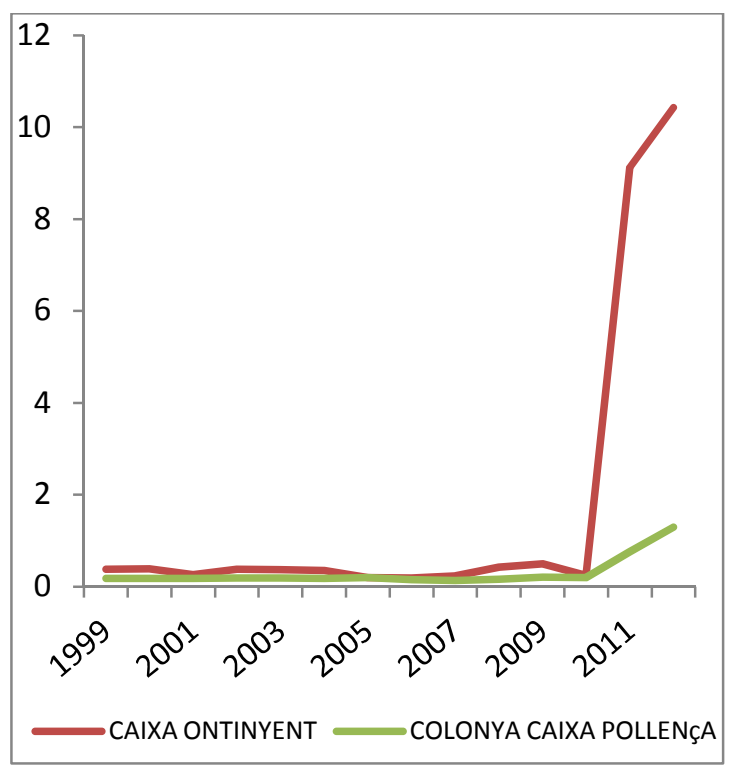

Fuente: Elaboración propia en base a los Anuarios Estadísticos de la CECA (1999-2012).

Si se analiza el gráfico 7, que recoge la evolución del gasto en obra social de las cajas de ahorros que constituyen el grupo 2, cabe destacar Kutxabank como la entidad que más invierte en Obra Social. No obstante, llama la atención la fuerte reducción experimentada en 2009. Lo anterior puede ser debido al SIP producido en 2010, que ha motivado el cambio de tendencia en la inversión en obra social. La segunda caja que ha visto incrementada la cuantía de la obra social es Caixabank, aunque su evolución ha sido más progresiva que la de Kutxabank. El resto de entidades ven reducida su obra social a partir del año 2009 o 2010, que puede deberse al período en que se haya producido su integración.

En el gráfico 8 se observa cómo aquellas entidades que no han tenido ningún proceso de integración han mantenido constante su gasto en Obra Social durante todo el período analizado, excepto en el año 2010, a partir del cual tiende a aumentar. Así, Caixa Ontinyent ha pasado de un nivel en gasto en Obra Social de 0,49 en 2009 a 10,42 en 2012, a pesar de que no ha sufrido ningún proceso de integración o fusión. Su negocio se basa en la prudencia y 
transparencia por lo que no está obligada a incrementar su capital ni a transformarse en un banco. Esta entidad es una de las dos cajas de ahorros españolas, junto con Caixa Pollença, que gestionan su actividad financiera directamente. Al tener un fondo de provisiones (reservas) suficiente no han tenido la necesidad de disponer de ayudas públicas. Por tanto, son entidades que pueden realizar mayores inversiones en Obra Social.

\subsubsection{Análisis de la solvencia de las cajas de ahorros}

La solvencia es una variable clave en el estudio de las entidades bancarias, y especialmente relevante en las situaciones de crisis, por múltiples razones, pero principalmente por ser uno de los objetivos de referencia en la reestructuración bancaria como consecuencia de las exigencias de Basilea III.

Si se analiza el gráfico 9 se observa cómo las tres entidades que han sido intervenidas por el FROB habían visto disminuido su porcentaje de solvencia notablemente; lo cual puede deberse a que en el proceso de traspaso al FROB afloraron activos dudosos que no estaban adecuadamente registrados anteriormente. Es el caso, por ejemplo, de Novagalicia Banco, que a pesar de que su nivel de 2012 ha supuesto una mejora respecto a 2010, ha experimentado fuertes fluctuaciones en su ratio de solvencia a lo largo del período analizado. Lo mismo ha ocurrido con las otras dos entidades que constituyen el grupo 0; así, Bankia, es una de las entidades menos solventes, habiendo pasado de tener unos niveles de solvencia de 0,04 en 2009 a -0,003 en 2012, por lo que ha sido esencial su nacionalización. Por último, Catalunya Banc tenía una solvencia de 0,04 en 2009 y en 2012 ha sido de 0,01.

Todo lo anterior ha sido uno de los factores clave para que estas entidades hayan sido intervenidas por el FROB, pues sus ratios de solvencia se encontraban en niveles insostenibles, muy por debajo de las exigencias internacionales de Basilea III y de los objetivos del Banco de España. 
Gráfico 9: Evolución de la solvencia en las cajas intervenidas por el FROB (Grupo 0)

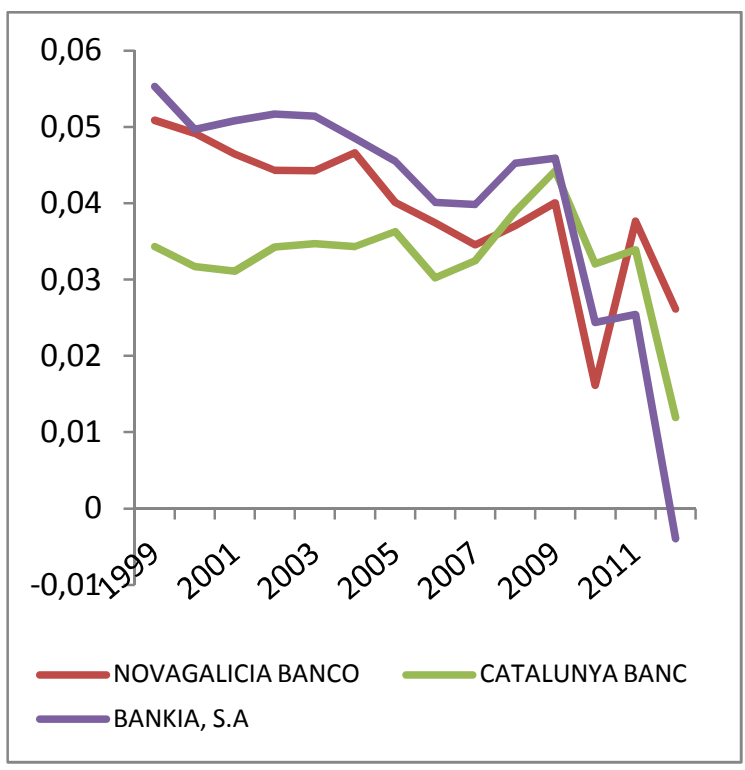

Fuente: Elaboración propia en base a los Anuarios Estadísticos de la CECA (1999-2012).
Gráfico 10: Evolución de la solvencia en las cajas deficitarias (Grupo 1)

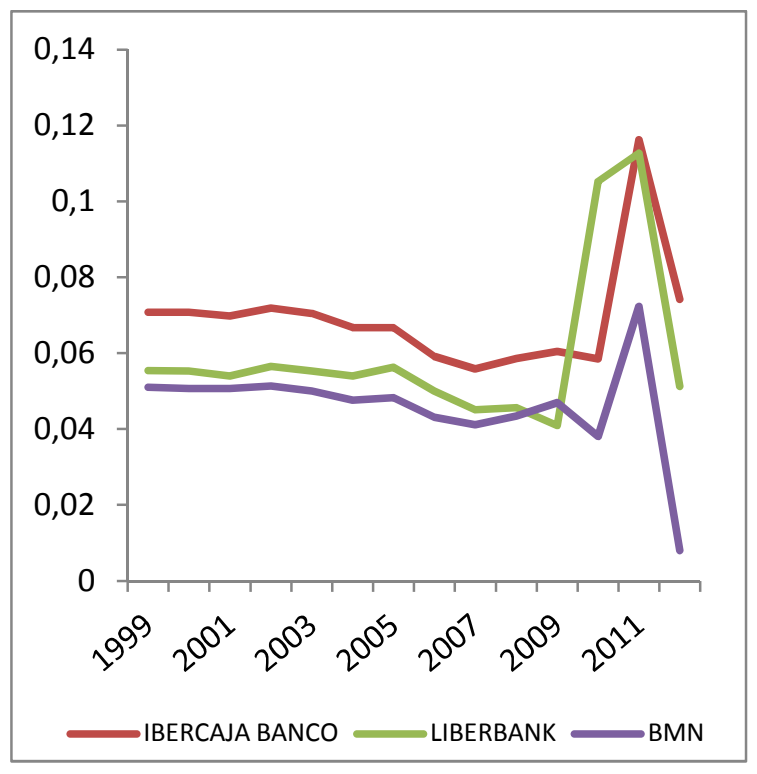

Fuente: Elaboración propia en base a los Anuarios Estadísticos de la CECA (1999-2012).

Si se analizan ahora las entidades con déficit de capital, recogidas en el gráfico 10, se observa que en este caso, la solvencia ha tenido sólo leves variaciones hasta el año 2009, momento a partir del cual aumenta para reducirse posteriormente. Así, gracias a las integraciones producidas a través de los SIP observamos cómo entidades como Ibercaja Banco o Liberbank ven incrementadas sus ratios de solvencia, llegando incluso a ser Ibercaja una de las tres entidades con mejor solvencia del conjunto de las cajas de ahorros. El caso de BMN es diferente, al pasar de tener un nivel de 0,04 en 2009 a 0,01 en 2012.

En el caso del denominado grupo 2, cuya evolución respecto a la solvencia queda reflejada en el gráfico 11, observamos que podríamos clasificar las entidades que lo forman en dos subgrupos diferenciados.

Por una parte, Kutxabank, Caixabank y Unicaja banco que han tenido una mejora respecto a la solvencia a lo largo del período estudiado, a pesar de que dicha ratio se reduce en el año 2011 para el caso de Unicaja Banco. Kutxabank destaca, como la entidad que mejor solvencia posee en este grupo, lo que puede ser consecuencia del SIP producido entre 2010 y 2011, por lo que podemos decir que el proceso de fusión por SIP ha sido muy favorable para esta entidad, habiendo pasado de tener un nivel de solvencia de 0,08 en 2009 a 0,14 en 2012. El caso de Caixabank también es destacable por haber ido aumentando a lo largo de los años, ya que es uno de los tres únicos bancos participados por las cajas de ahorros que tienen sus 
necesidades cubiertas de capitalización y no necesita ayudas públicas.

Por otra parte, destaca el caso de Banco CAM y Unnim, cuyos niveles de solvencia han ido disminuyendo progresivamente a lo largo de los 13 años analizados. Lo anterior fue una de las causas para que dichas entidades fueran integradas en diferentes bancos. En el Banco Sabadell en el caso del Banco CAM y en el BBVA en cuanto a Unnim Banc se refiere.

Gráfico 11: Evolución de la solvencia en las cajas sin déficit (Grupo 2)

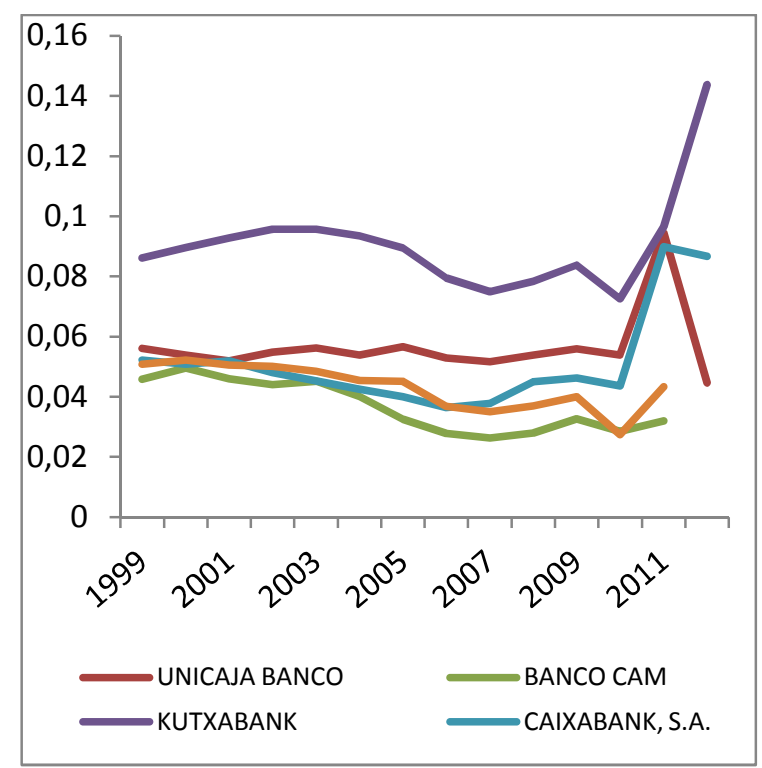

Fuente: Elaboración propia en base a los Anuarios Estadísticos de la CECA (1999-2012).
Gráfico 12: Evolución de la solvencia en las cajas sin proceso de integración (Grupo 3)

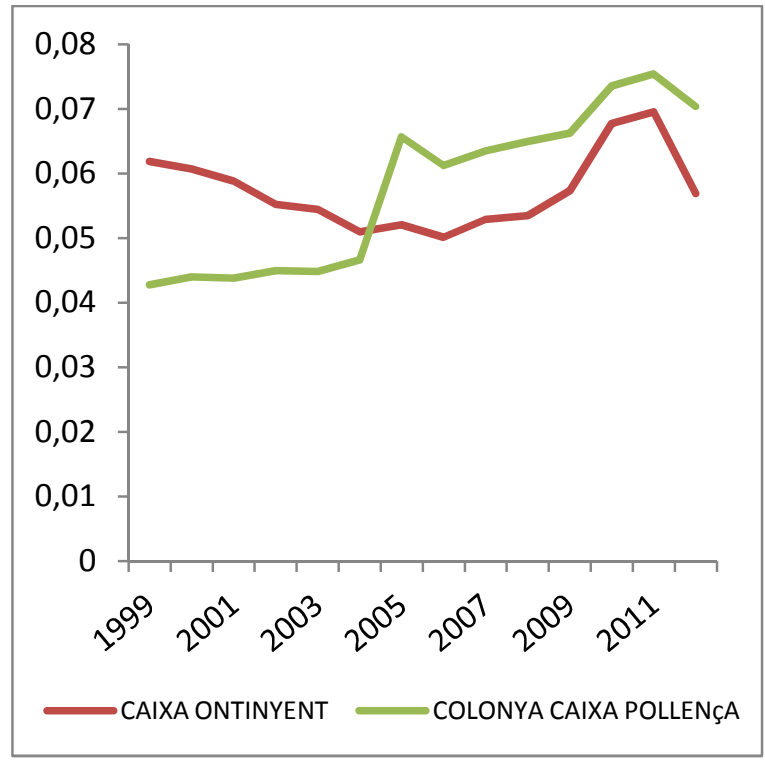

Fuente: Elaboración propia en base a los Anuarios Estadísticos de la CECA (1999-2012).

Por último, cuando se estudia el gráfico 12, en el que se recoge la evolución de la solvencia de las cajas de ahorros que no han experimentado ningún proceso de integración, podemos observar que en este caso, la situación ha sido variable. Destaca el comportamiento de Colonya Caixa Pollença que ha ido mejorando sus niveles de solvencia desde el año 1999 hasta 2012, pese a haber tenido descensos poco significativos tanto en el año 2005 como en el 2012. Por último, vemos cómo en el caso de Caixa Ontinyent la ratio de solvencia ha ido disminuyendo desde 1999 hasta 2006, para aumentar posteriormente hasta el año 2010 y volver a disminuir a partir de dicho año. Por tanto, se trata de una evolución bastante variable. 


\subsubsection{Análisis de la brecha financiera de las cajas de ahorros}

Esta variable muestra la relación entre los créditos y los débitos o depósitos de la entidad (Doumpos y Zopounidis, 2010; Palomo y Sanchis, 2010); existiendo brecha cuando su valor es mayor que la unidad o $100 \%$, lo cual indica que el volumen de créditos supera a los depósitos captados. La brecha financiera puede caracterizar un determinado comportamiento en el modelo de negocio - mayor brecha financiera se puede corresponder con un modelo más activo, expansivo y apalancado que puede ser adecuado en épocas de bonanza económica-, si bien aumenta la vulnerabilidad ante un cambio de ciclo económico. Teniendo en cuenta lo anterior, se ha considerado esencial por englobar el período analizado un cambio de ciclo y por ser una variable comúnmente estudiada para analizar la viabilidad de las entidades financieras.

Gráfico 13: Evolución de la brecha financiera en las cajas intervenidas por el FROB (Grupo $0)$

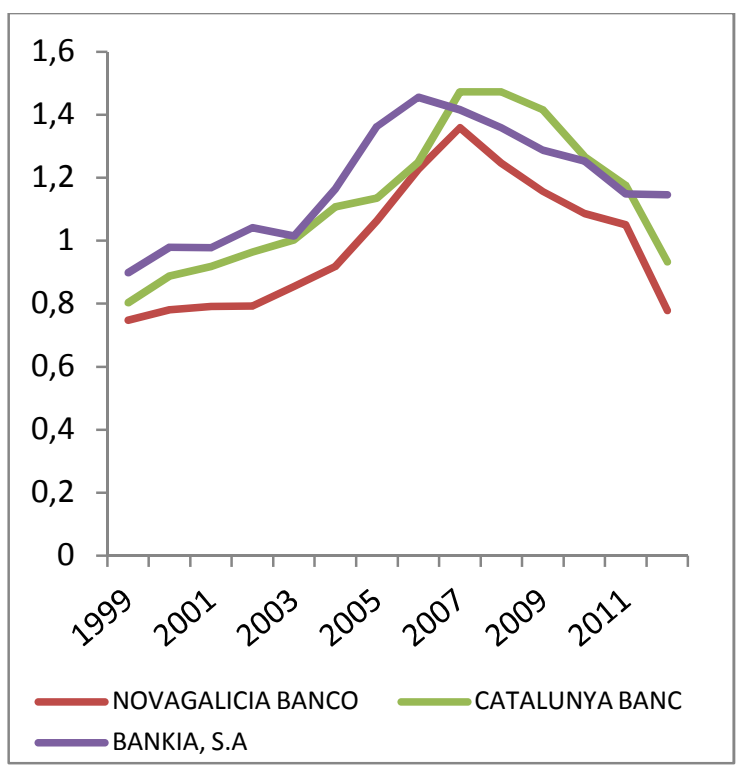

Fuente: Elaboración propia en base a los Anuarios Estadísticos de la CECA (1999-2012).
Gráfico 14: Evolución de la brecha financiera en las cajas deficitarias (Grupo 1)

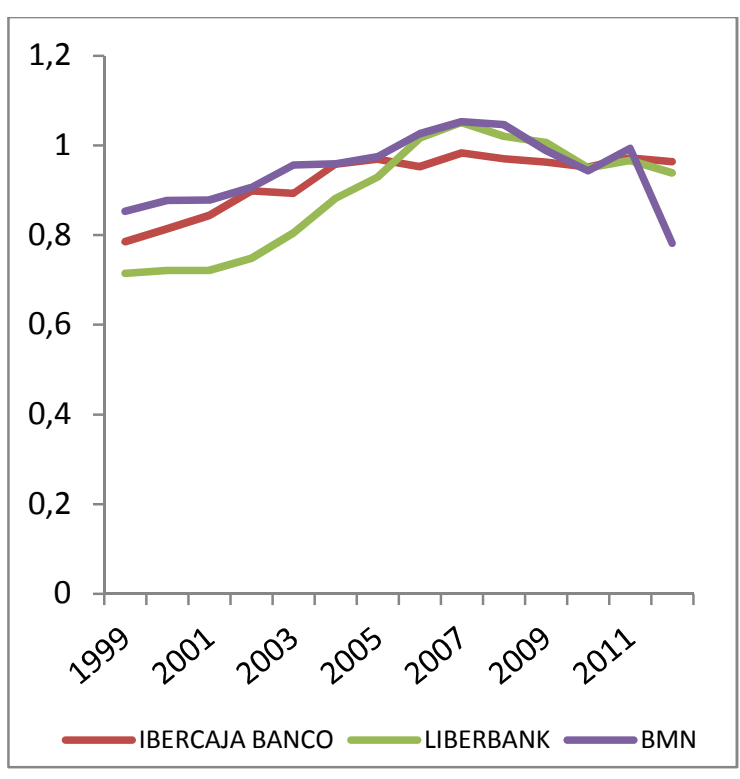

Fuente: Elaboración propia en base a los Anuarios Estadísticos de la CECA (1999-2012).

En el caso de las entidades intervenidas por el FROB (Gráfico 13), vemos cómo se observa perfectamente el cambio en la tendencia de los niveles de brecha financiera, antes y después de la crisis. Se trata de un cambio bastante brusco por haber sido entidades con un modelo de negocio muy expansivo y apalancado, inviable tras la crisis financiera. Lo anterior ha podido ser otra de las causas que han provocado la nacionalización de entidades como Bankia, Novagalicia Banco o Catalunya Banc. 
Cuando se estudia el gráfico 14, se aprecia cómo las oscilaciones son menores que en el grupo anterior. Destaca el caso de Ibercaja, que ha ido aumentando progresivamente su brecha. Dicho incremento puede ser causa de los procesos de integración producidos en esta entidad. Lo mismo ocurre en el caso de Liberbank, mientras que es BMN la entidad que posee una peor evolución.

Gráfico 15: Evolución de la brecha financiera en las cajas sin déficit (Grupo 2)

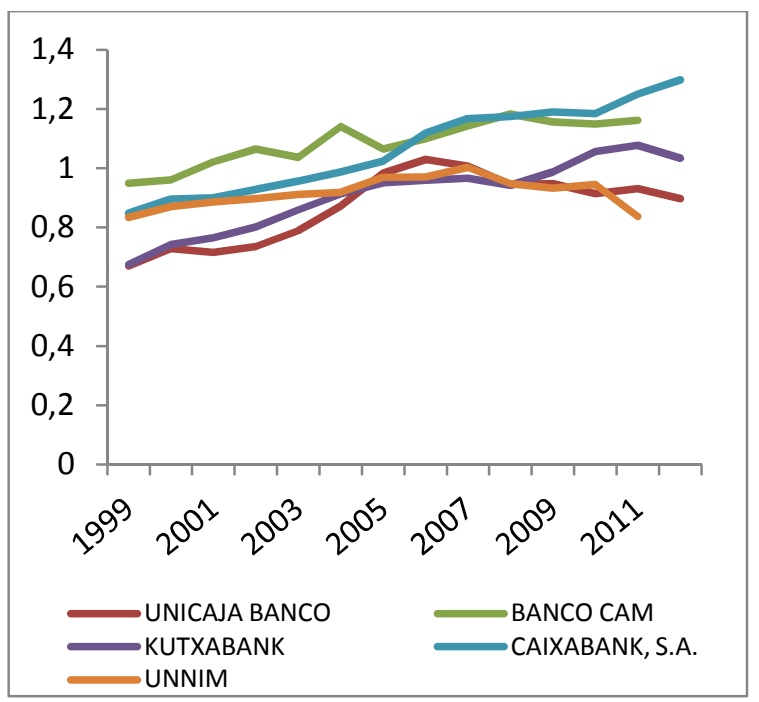

Fuente: Elaboración propia en base a los Anuarios Estadísticos de la CECA (1999-2012).
Gráfico 16: Evolución de la brecha financiera en las cajas sin proceso de integración (Grupo 3)

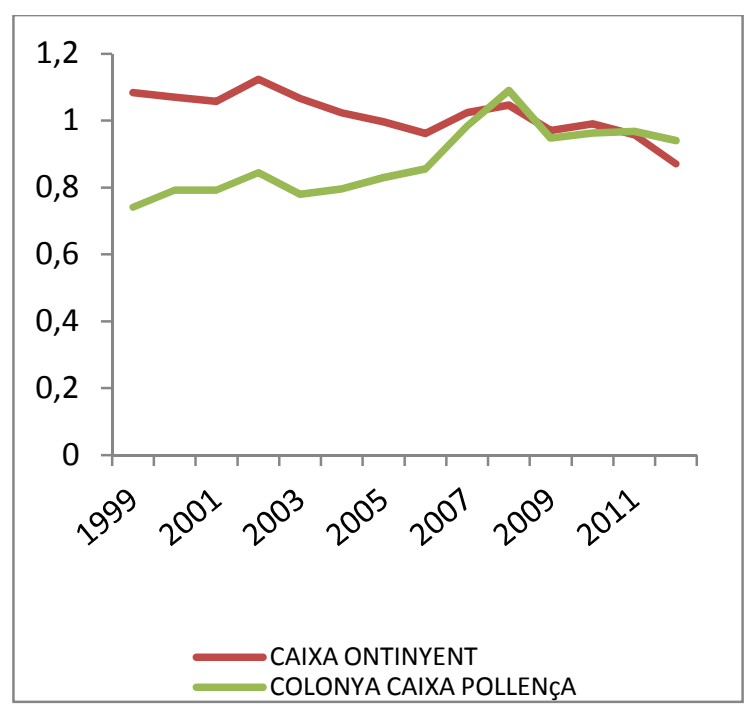

Fuente: Elaboración propia en base a los Anuarios Estadísticos de la CECA (1999-2012).

El gráfico 15 permite apreciar la situación de las cajas sin déficit, respecto a las que destacan entidades como Kutxabank y Caixabank que han visto experimentado una evolución contracíclica de su brecha financiera. Así, a pesar de los momentos de crisis han apostado por un modelo de negocio expansivo, incrementando, sobre todo en el caso de Caixabank, los créditos respecto a los depósitos. En el resto de entidades la variabilidad no ha sido excesiva.

Para terminar con el análisis de la brecha financiera se pasa a estudiar aquellas entidades que no han experimentado ningún proceso de integración, como es el caso de Caixa Ontinyent y Caixa Pollença. Ambas cajas parten de niveles distintos de brecha para terminar el período con un nivel muy parecido, siendo algo superior el de Caixa Pollença.

Una vez se ha analizado la evolución de las cuatro variables objeto de estudio es posible pasar a exponer las conclusiones que se extraen de la investigación realizada. 


\section{CONCLUSIONES}

Como consecuencia de la crisis financiera y con el objetivo de conseguir los niveles de solvencia y liquidez exigidos por el nuevo cuerpo normativo que afecta al negocio bancario, las entidades financieras han debido afrontar una necesaria reestructuración, que ha sido especialmente aguda en el sector de las cajas de ahorros. Este proceso de reestructuración se ha llevado a cabo mediante fusiones, absorciones y a través de Sistemas Institucionales de Protección (SIP) que han derivado en una bancarización del sector y en la práctica desaparición de la figura original de las cajas de ahorros.

Solamente dos del total de estas entidades han conseguido conservarse como tales, sin necesidad de haberse integrado con otras entidades ni de convertirse en bancos (Caixa de Ontinyent y Colonya Caixa Pollença); pero representan tan solo un $0,1 \%$ del negocio bancario del total de las cajas de ahorros españolas. Estas dos entidades han sobrevivido en parte por su tamaño, al ser las más pequeñas del sector, pero principalmente por ser las dos únicas entidades que cumplen con los criterios de banca minorista y de limitación geográfica en que se ha basado tradicionalmente el modelo de negocio de las cajas de ahorros.

El resto de entidades que han intervenido en procesos de integración alcanzan el 99,9\% del peso del sector y operan actualmente a través de bancos, por lo que tienen acceso a mercados de cotización a través de la emisión de capital.

Actualmente, según la Ley de Cajas de Ahorros, estas entidades deben convertirse en fundaciones bancarias especiales. Ellas sólo podrán actuar sobre la administración o dirección de la Obra Social en los casos que ésta exista.

Con las fusiones y otras formas de concentración citadas se ha pretendido ganar posición competitiva (a través del aumento de su escala), incrementar su cuota de mercado (disminuyendo ineficiencias), pero sobre todo una mejora sustancial de la solvencia y el posible mejor acceso al mercado de capital. Asimismo, otras entidades se han unido para conseguir las ayudas públicas, por el ejemplo las procedentes del FROB, para poder conseguir la liquidez perdida debido a la crisis económico-financiera.

Tras el análisis realizado, se pueden extraer varias conclusiones principales. Así, las entidades que más se han visto afectadas en sus resultados han sido Caixabank, Kutxabank y Ontinyent: 
- Caixabank ha mejorado su eficiencia en 2,9 puntos, la solvencia en 0,04 puntos y la brecha financiera en 0,04 aproximadamente entre 2009 y 2012.

- Kutxabank con una mejora en solvencia de 0,06 puntos de diferencia aproximadamente, en gasto de Obra Social ha experimentado un incremento de 1,57 puntos y 0,06 puntos en la brecha financiera.

- Caixa Ontinyent: a pesar de no haber experimentado ningún proceso de integración ha visto mejorada su eficiencia en 8,53 puntos en 2012 respecto al 2009 y un aumento en gasto de Obra Social de 9,93 puntos.

Este análisis permite confirmar que las únicas entidades que han mejorado su eficiencia técnica después de los procesos de integración mencionados anteriormente han sido Caixabank y Caixa Ontinyent. Las entidades que han mejorado su gasto en Obra Social: Kutxabank, Caixabank, Caixa Ontinyent y Colonya Caixa Pollença; las entidades que han mejorado su solvencia: Ibercaja, Liberbank, Kutxabank, Caixabank y Unnim; y, las entidades que han mejorado su brecha financiera han sido: Kutxabank, Caixabank, Ibercaja y CAM.

Por tanto, el resultado del análisis realizado permite confirmar que no todas las cajas de ahorros han conseguido los objetivos que perseguían en un principio a la hora de integrarse o transformarse, que era, sustancialmente, la mejora en su eficiencia técnica y en la solvencia. Esto conduce a una valoración sobre el éxito relativo, cuando no fracaso relativo, de este importante y trascendental proceso acaecido en el sistema bancario español.

* Los autores manifiestan que han trabajado por igual en la realización del artículo.

\section{BIBLIOGRAFÍA}

BANCO DE ESPAÑA (2012) Regulación Financiera: Cuarto trimestre de 2011. Boletín Económico del Banco de España, Enero de 2012, pp. 1-140.

BERGER, A.N.; DE YOUNG, R. Y UDELL, G.F., (2001) Efficiency barriers to the consolidation of the European financial services industry. European Financial Management, Vol. 7, № 1, pp. 117-130.

CONFEDERACIÓN ESPAÑOLA DE LAS CAJAS DE AHORROS (2015) CECA Sector. Regulatory and Financial Outlook. November, 15th. Recuperado el 17 noviembre de 2015 de URL http://www.ceca.es/wp-content/uploads/2015/11/Regulatory-and-financialoutlook-11-11-2015.pdf 
CONFEDERACIÓN ESPAÑOLA DE LAS CAJAS DE AHORROS, varios años. Anuario Estadístico de las Cajas de Ahorros. Madrid: CECA.

CSBB (2011) Basel III: A global regulatory framework for more resilient banks and banking systems - revised version June 2011 [Versión española: Basilea III: Marco regulador global para reforzar los bancos y sistemas bancarios. Recuperado el 10 febrero de 2014 de URL http://www.bis.org/publ/bcbs189_es.pdf

DOUMPOS, M. Y ZOPOUNIDIS, C. (2010) A multicriteria decision support system for bank rating. Decision Support Systems, Vol. 50, No 1, pp. 55-63.

EFTHYVOULOU, G. Y YILDRIM, C. (2014) Market power in CEE banking sectors and the impact of the global financial crisis. Journal of Banking and Finance, Vol. 40, № 3, pp. $11-27$.

FUENTES, I. (2003) Un análisis de las fusiones bancarias recientes (1997-2000) en España. Boletín Económico del Banco de España, julio-agosto, pp. 71-78.

GUTIÉRREZ, M.; PALOMO, R. Y FERNÁNDEZ, G. (2013) Las cajas de ahorros españolas: ¿una pretendida reordenación bajo criterios de racionalidad económica y social?. Cuadernos de Economía y Dirección de la Empresa, № 16, pp. 250-258.

GUTIÉRREZ, M.; PALOMO, R. Y ROMERO, M. (2012) La expansión territorial como factor motivador de la reestructuración del sistema financiero español: el caso de las cajas de ahorros y las cooperativas de crédito. REVESCO. Revista de Estudios Cooperativos, $\mathrm{N}^{\circ}$ 107, pp. 7-34.

GUTIÉRREZ, M. (2011) Análisis del desempeño en la reordenación del sistema bancario español: el caso de las cajas de ahorros. Tesis doctoral. Madrid: Universidad Nacional de Educación a Distancia.

HOMMA, T.; TSUTSUI, Y. Y UCHIDA, H. (2014) Firm growth and efficiency in the banking industry: A new test of the efficient structure hypothesis. Journal of Banking and Finance, Vol. 40, № 3, pp. 143-153.

MIRALLES, J.L. Y DAZA, J. (2011) La reestructuración de las Cajas de Ahorros en el Sistema Bancario Español. Boletín de la Real Academia de Extremadura de las Letras y las Artes, $\mathrm{N}^{\circ} 19$, pp. 507-557.

PALOMO, R., SANCHIS, J.R. Y GUTIÉRREZ, M., (2011) Efectos de la crisis financiera sobre la innovación en la reorganización de los sistemas bancarios: los sistemas institucionales de protección en las entidades financieras de ámbito territorial. Innovar Journal, Vol. 21, №39, pp. 179-190.

PALOMO, R. Y SANCHIS, J. R. (2010) Efectos de las fusiones sobre la concentración y la 
eficiencia bancaria: el caso de las cajas rurales y los retos de la crisis financiera. Revista Española de Financiación y Contabilidad, XXXIX, Vol. 39, Nº 146, pp. 289-319.

RHOADES, S.A. (1998) The efficiency effects of bank mergers: an overview of case studies of nine mergers. Journal of Banking \& Finance, Vol. 22, N 3, pp. 273-291.

RUGHOO, A. Y SARANTIS, N. (2014) The global financial crisis and integration in European retail banking, Journal of Banking and Finance, Vol. 40, № 3, pp. 28-41.

WYMAN O. (2012) Asset quality review and bottom-up stress test exercise. Madrid: Marsh \& McLennan Companies.

\section{NORMATIVA CONSULTADA}

Real Decreto-Ley 24/2012, de 31 de Agosto, Restructuración y Resolución Ordenada de Entidades de Crédito $3^{\text {a }}$ Fase de la Reforma del Sistema Financiero Español. Boletín Oficial del Estado. 1 septiembre 2012, núm. 210.

Real Decreto-ley 6/2010, de 9 de abril, de medidas para el impulso de la recuperación económica y el empleo. Boletín Oficial del Estado. 13 de abril de 2010, núm. 89. 